\title{
Competitividade do sistema produtivo do turismo em Bonito, MS, a partir de uma visão baseada em recursos*
}

\author{
Competitiveness of tourism productive system in Bonito, MS, Brazil, from a \\ resource-based view
}

\section{Compétitivité système productif du tourisme au Bonito, MS, Brésil, départ d'une vue axé sur les ressources}

\author{
Competitividad del sistema productivo de turismo en Bonito, MS, Brasil, desde una visión \\ basada en recursos
}
Dyego de Oliveira Arruda**
(dyego.arruda@gmail.com)

Gustavo Magalhães de Oliveira***

(gustavomoliv@gmail.com)

Milton Augusto Pasquotto Mariani***

(miltmari@terra.com.br)

Recebido em 26/09/2013; revisado e aprovado em 22/11/2013; aceito em 12/02/2014

\begin{abstract}
Resumo: Com o escopo de defender e consolidar suas posições estratégicas, sobretudo ao se considerar a ampliação da concorrência nos mercados turísticos, observa-se que os sistemas produtivos do turismo lançam mão de novas e variadas formas organizacionais, classificadas como recursos no presente trabalho. Partindo dessa premissa, este estudo tem como objetivo geral classificar os recursos disponíveis dentro do sistema turístico da cidade de Bonito, em Mato Grosso do Sul, Brasil, bem como verificar qual o nível de competitividade gerado por eles. Aplicou-se como base teórica o modelo Valor, Raridade, Imitabilidade e Organização (VRIO), da Visão Baseada em Recursos (VBR). Foram pesquisadas quatro agências de viagens de Bonito, além de representantes dos ambientes institucional e organizacional local/regional. Observou-se que os recursos que trazem maior desenvolvimento e vantagem sustentada à Bonito são: a configuração do Voucher Único, os atrativos locais, além do próprio território.

Palavras-chave: Visão baseada em recursos. Sistema turístico. Desenvolvimento Local.
\end{abstract}

Abstract: In order to defend and consolidate their strategic positions, particularly when considering the expansion of competition in the tourism market, we observe that the tourism productive systems are using new and varied organizational forms, classified as resources in the present work. From this premise, this study aims to classify the overall resources available within the tourism system in the city of Bonito, Mato Grosso do Sul, Brazil, as well as to identify the degree of competitiveness generated by these resources. We applied the model named Value, Rarity, Inimitability and Organization (VRIO), in the scope of Resource Based View (RBV). We surveyed four travel agencies in Bonito, and representants of institutional and organizational environments in the city investigated. We observed that the features that bring greater development and lead sustained competitiveness to Bonito are: the organizational configuration of 'Voucher Único'; the local attractions; and the configuration of the territory in Bonito. Key words: Resource based view. Tourist system. Local Development.

Résumé: Afin de défendre et de consolider leurs positions stratégiques, en particulier lorsque l'on considère l'expansion de la concurrence dans le marché du tourisme, nous observons que les systèmes productifs de tourisme utilisent de nouvelles formes d'organisation et variés, classés comme ressources dans le présent ouvrage. A partir de cette prémisse, cette étude vise à classer l'ensemble des ressources disponibles au sein du système touristique dans la ville de Bonito, Mato Grosso do Sul, Brésil, ainsi que d'identifier le degré de compétitivité générés par ces ressources. Nous avons appliqué le modèle nommé Valeur, Rareté, Miraculeux et de l'Organisation (VRIO), dans le cadre de Vision Basée sur les Ressources (VBR). Nous avons interrogé quatre agences de voyage à Bonito, et representants des milieux institutionnels et organisationnels de la ville étudié. Nous avons observé que les caractéristiques qui apportent un plus grand développement et mener une compétitivité durable à Bonito sont: la configuration organisationnelle de 'Voucher Único'; attractions locales, et la configuration du territoire à Bonito.

Mots-clés: Vision basée sur les ressources. Système touristique. développement local.

Resumen: Con el fin de defender y consolidar sus posiciones estratégicas, sobre todo al considerar la ampliación de la competencia en los mercados turísticos, se observa que los sistemas productivos de turismo utilizan formas organizativas nuevas y variadas, que se clasifica como recursos en el presente trabajo. Desde esta premisa, este estudio tiene como objetivo clasificar a los recursos organizacionales disponibles en el sistema turístico de la ciudad de Bonito, Mato Grosso do Sul, Brasil, así como identificar el grado de competitividad generada por esos recursos.

\footnotetext{
* Os autores contribuíram de forma equânime e coordenada para a realização do presente trabalho. Nesse sentido, a disposição da sequência de autoria do artigo foi feita a partir da ordem alfabética dos nomes dos autores, apenas por uma questão de critério.

** Universidade de São Paulo (USP), Ribeirão Preto, SP, Brasil; Instituto Federal do Mato Grosso, Pontes e Lacerda, MT, Brasil.

*** Universidade Federal de Mato Grosso do Sul (UFMS), Campo Grande, MS, Brasil.
} 
Se aplicó el modelo teórico llamado Valor, Rareza, Imitabilidad y Organización (VRIO), que pertenece a la Visión Basada en Recursos (VBR). Fueron entrevistados cuatro agencias de viajes en Bonito, además de representantes de los ambientes institucionales y organizacionales de la ciudad de Bonito. Se observó que las características que aportan un mayor desarrollo y vantajas competitivas sostenibles a Bonito son: el sistema de 'Voucher Único'; las atracciones locales; además del propio territorio turístico.

Palabras clave: Visión basada en recursos. Sistema turístico. Desarrollo Local.

\section{Introdução}

A supremacia de um modelo econômico calcado no livre comércio e na paulatina desregulamentação de setores produtivos outrora embasados em regras rígidas, além do consequente acirramento do padrão de competição em uma série de mercados (dentre os quais, o próprio mercado de turismo), são fatores que, atuando de forma conjunta, relegam às organizações a necessidade de refletirem acerca das estratégias e dinâmicas geradoras de competitividade em suas respectivas esferas de atuação (ARRUDA, 2013).

A partir dos seminais trabalhos de Barney (1986 e 1991), pode-se entender a competitividade (ou vantagem competitiva, nos termos do autor) como sendo a resultante de recursos ou competências detidas pelas firmas e/ ou conjunto de firmas organizadas em um dado território, que relega a essas empresas ou sistemas de empresas uma posição vantajosa em relação a seus concorrentes (reais ou potenciais), no âmbito da disputa pelos mercados. Dentre tais recursos ou competências geradoras de vantagem competitiva, pode-se elencar uma série de ativos tangíveis ou intangíveis, dentre os quais: habilidades de gestão organizacional; rotinas e processos organizacionais; controle e disseminação de informações no âmbito das organizações; além de uma série de outras questões não raro condicionadas às dinâmicas do território, nos quais as organizações exercem suas atividades (BARNEY et al., 2011).

Quando se avalia especificamente as dinâmicas dos mercados de turismo, percebe-se que tal atividade apresenta um caráter marcadamente sistêmico, envolvendo organizações dos mais variados setores econômicos. Nesse ínterim, Beni (2003) ressalta que o turismo carece da participação de uma série de agentes (dentre os quais operadoras e agências de viagens, hotéis, restaurantes, guias de turismo etc.) no cenário da formatação e criação de diferenciais no seio do produto turístico, o qual ainda necessita de canais coesos de distribuição para que possa chegar até o consumidor final do turismo.

Dentre os elementos que determinam constantes desafios às organizações nos mercados de turismo, Beni (2003) e Arruda (2013) citam as seguintes questões: intempéries nas cotações do dólar e sua marcante influência no turismo, sobretudo quando se considera o turismo internacional; o constante aparecimento de mercados emergentes de turismo, não raro a partir de fatores e/ ou conjunturas temporárias (tais como os mercados de turismo de grandes eventos, turismo religioso ou o próprio ecoturismo); as mudanças nos hábitos e comportamentos de consumo dos turistas; além de uma série de outras questões, em muitos casos de caráter territorial. Assim sendo, observa-se que as organizações - principalmente nos mercados turísticos mais maduros - precisam constantemente defender suas posições estratégicas, majoritariamente a partir do desenvolvimento e/ou manutenção de vantagens competitivas, a fim de que o sistema produtivo do turismo, como um todo, apresente níveis satisfatórios de competitividade em relação a mercados concorrentes ou substitutos (MASSUKADO-NAKATANI; TEIXEIRA, 2009).

Quanto se remete a análise especificamente ao caso do sistema turístico na cidade de Bonito, no Estado de Mato Grosso do Sul, nota-se que tal destino revela-se como um dos mais relevantes polos do ecoturismo regional e nacional. Porém nota-se que o turismo em Bonito, principalmente no período mais recente, tem sua posição estratégica ameaçada não raro por conta da emergência de outros destinos turísticos também voltados ao ecoturismo, tais como Nobres, no Estado de Mato Grosso; e Brotas, no interior do Estado de São Paulo (MARIANI; ARRUDA, 2013). Portanto faz-se necessária uma análise mais detida acerca dos fatores determinantes ou que podem determinar vantagens competitivas ao sistema turístico de Bonito, com o escopo de 
que sua posição estratégica como importante polo de ecoturismo nacional seja mantida e/ ou cada vez mais consolidada.

O presente artigo usa, como base teórica, a chamada Visão Baseada em Recursos (VBR) - ou Resource Based View (RBV), nos termos em inglês - como forma de avaliar a importância dos aspectos organizacionais do sistema turístico de Bonito, no âmbito da geração de vantagens competitivas (FOSS; FOSS, 2005).

As reflexões que nortearam o presente trabalho foram embasadas no seguinte questionamento de pesquisa: quais os recursos indispensáveis à formatação dos produtos turísticos, desde a concepção da atratividade turística até a chegada do produto turístico ao consumidor final, que relegam vantagem competitiva a este sistema turístico?

Logo - municiado da supracitada problemática de pesquisa - o presente trabalho tem como objetivo geral analisar a competitividade do sistema produtivo do turismo em Bonito, a partir dos recursos intrínsecos a esse sistema turístico. Especificamente, pretendese identificar os recursos que relegam ou podem relegar vantagens competitivas ao sistema turístico de Bonito, com a consequente descrição do caráter sistêmico e holístico sob os quais esses recursos são geridos estrategicamente. Por fim, almeja-se identificar possíveis falhas e/ou oportunidades no âmbito do sistema turístico em análise.

A relevância da presente análise reside na premissa de se entender, por meio dos recursos, as dinâmicas de estruturação e gestão do sistema turístico de Bonito, subsidiando possíveis tomadas de decisões estratégicas no seio da gestão desse importante destino turístico.

Em suma, o presente trabalho está estruturado em cinco partes constitutivas, além desta introdução. Na primeira parte, apresenta-se um breve levantamento dos conceitos e especificidades acerca da vantagem competitiva, naturalmente, no seio da própria Visão Baseada em Recursos. Na segunda parte, expõem-se características e elementos analíticos acerca do objeto de estudos, qual seja: o sistema produtivo do turismo em Bonito, MS. Na terceira parte, descrevem-se os procedimentos metodológicos que embasaram a presente pesquisa; ao passo que, na quarta parte, elucidam-se os resultados. Por fim, na quinta e última parte, apresentam-se algumas considerações de caráter mais conclusivo, porém sem a pretensão de encerrar e/ou esgotar o presente assunto.

\section{Competitividade: algumas características basilares}

A partir do surgimento e ampliação de novos mercados e setores econômicos, emergem, dentro da literatura em economia e gestão organizacional, formas inéditas de se avaliar e almejar posições competitivas superiores às situações de seus rivais.

Quando se analisa a temática da posição competitiva de uma organização, observa-se que o mainstream analítico não raro condiciona tais avaliações à questão intraorganizacional, tais como se pode depreender dos estudos de Penrose (1959), Wernerfelt (1984) e Barney (1986). Porém a emergência de uma análise sistêmica, com a paulatina evidência de que as organizações estruturavam-se de forma interdependente e cooperada, fez com que surgisse na literatura uma corrente de teóricos - sobretudo capitaneados por Oliver (1997) calcados na avaliação da posição competitiva dos próprios sistemas produtivos, cuja tônica calcava-se no relacionamento e cooperação interorganizacional.

Farina (1999), ao avaliar a competitividade no âmbito de uma análise sistêmica, pondera que são quatro as características da análise da competitividade no âmbito do estudo dos sistemas de produção:

- A sobrevivência do segmento, como um todo, é necessária, mesmo que várias de suas firmas não possam competir satisfatoriamente;

- Os vários elos de um determinado sistema produtivo apresentam graus distintos de competitividade. Mesmo assim, seus efeitos e implicações são de caráter sistêmico (por exemplo, a baixa performance de um determinado segmento de um sistema tem a capacidade de comprometer os outros segmentos do mesmo sistema - só para citar um caso factível);

- Formação de subsistemas de acordo com o grau de especificidade dos ativos que irão competir entre si e também com o mercado global. 
- A ascensão de grupos estratégicos, não raro dentro de um mesmo segmento e, portanto, dentro de um mesmo sistema.

Apesar da grande quantidade de conhecimento, informações e técnicas disponíveis, ainda são bastante visíveis as imperfeições nos modelos de mensuração da competitividade no âmbito de uma firma ou de um sistema de produção. Dentre os fatores que concorrem para a dificuldade na avaliação da competitividade, estão: a marcante influência das políticas públicas na garantia de um ambiente competitivo; a existência de vários graus de dependência entre os agentes organizacionais; além da própria imobilidade e heterogeneidade da indústria.

Não obstante os complicadores supracitados, observa-se que um dos modelos mais usuais de avaliação da competitividade é a chamada Visão Baseada em Recursos (VBR), que possui ideias formadas por meio dos trabalhos de Barney (1991) e Wernerfelt (1984), com enfoque nos recursos organizacionais e suas consequentes capacidades, singularidades e sinergias no escopo da geração de vantagens competitivas.

Uma importante implicação do presente estudo, sobretudo com base em Arruda (2013) e Mariani e Arruda (2013), é a argumentação de que o território - entendido como o espaço de estabelecimento de relação entre os mais variados agentes, a partir da existência de laços de identidade entre si - pode representar uma fonte de vantagem competitiva aos sistemas produtivos, na medida em que concorre para a minimização dos custos de operacionalização do sistema e, por conseguinte, amplia a eficiência do sistema de produção, como um todo. Em suma, tais aspectos serão mais detidamente avaliados nas etapas subsequentes deste trabalho.

\subsection{Competitividade a partir de uma Visão Baseada em Recursos}

Quando se avalia a geração de vantagens competitivas no escopo de sistemas de produção, faz-se necessário remontar à avaliação das próprias dinâmicas de coordenação e governança dos sistemas de produção, cujas raízes teóricas estão nos seminais trabalhos de Coase (1937) e Williamson (1985 e 1996).

Os supracitados autores, ao explicar natureza da firma e o caráter contratual sob o qual as organizações realizam transações entre si, inauguram a chamada Nova Economia Institucional (NEI), cujo cerne analítico estaria na consideração de que os agentes econômicos estabelecem interações a partir de três princípios básicos: dos pressupostos comportamentais (oportunismo e racionalidade limitada); dos atributos da transação (frequência, incerteza e especificidade de ativos); além das dinâmicas do ambiente institucional e organizacional que tutela a transação entre as organizações.

A NEI possui basicamente dois focos analíticos no âmbito do estudo das instituições: uma abordagem macroinstitucional e uma outra microinstitucional. A primeira abordagem, sobretudo a partir das reflexões de Douglass North (1991 e 2004), trata dos estudos das instituições que condicionam o próprio comportamento dos indivíduos, não raro a partir de regras tácitas e arraigadas de viés cultural. O mesmo autor, quando se deteve no estudo das macroinstituições, tinha como premissa levantar subsídios que explicavam os vários níveis de desenvolvimento entre os países (especialmente dos países europeus e dos Estados Unidos em relação às nações de economia mais atrasada).

O ramo microinstitucional da NEI, principalmente com base nas análises de Williamson (1979, 1985, 1996 e 2000), Barzel (1982) e Barney (1991), tem como premissa a análise das estruturas de governança e dinâmicas específicas de coordenação entre os agentes, enfocando o estudo dos contratos e da estratégia das firmas. Percebe-se que os estudos microinstitucionais da NEI foram aqueles que ganharam sobremaneira atenção dos pesquisadores, majoritariamente em quatro linhas básicas de investigação: a Economia dos Custos de Transação (ECT); a Teoria do Agente-Principal; a Teoria dos Direitos de Propriedade; além da Visão Baseada em Recursos (VBR) ${ }^{1}$.

A partir do modelo da Visão Baseada em Recursos, a procura pela vantagem competitiva no seio das organizações ou sistemas

\footnotetext{
$\overline{1}$ O presente trabalho não tem como escopo apresentar as especificidades do corpo teórico da NEI. Objetiva-se apenas situar o conceito e dinâmicas da competitividade e da Visão Baseada em Recursos no seio daquela teoria. Para maiores informações acerca da NEI e seus aspectos determinados, sugere-se consultar Arruda (2013).
} 
de produção ficou determinada pela avaliação dos recursos intrínsecos às organizações ou sistemas, conforme já se fez menção supracitadamente. Nesse ínterim, no seio da VBR, surgiu o modelo VRIS - de Valor, Raridade, Imitabilidade e Substitutibilidade - que avalia cada recurso organizacional a partir dos elementos ponderados, que seriam fontes importantes de geração de vantagem competitiva (BARNEY, 1991).

Para Barney e Hesterly (2007), recursos são ativos tangíveis ou intangíveis que serão utilizados como ferramentas para criar, programar, adaptar e transformar diferentes estratégias. Em suma, os recursos podem ser classificados de quatro maneiras distintas:

- Recursos Financeiros: capital advindo de qualquer fonte - empreendedores, acionistas, bancos, credores, entre outros.

- Recursos Físicos: tecnologia intrínseca à infraestrutura dos diversos departamentos em conjunto com a facilidade de obtenção de matérias-primas diante da localização geográfica.

- Recursos Individuais: também conhecidos como recursos humanos, inclui conhecimento do quadro de colaboradores, habilidade de aprendizagem, facilidade em resolução de conflitos, competência de relacionamento.

- Recursos Organizacionais: que enfatizam a sinergia entre as ações formais e informais dos diversos degraus da hierarquia organizacional, dando suporte às ações de planejar, coordenar e controlar.

Já as capacidades ficam explicitadas na forma de gerenciar os recursos em si, a partir de suas singularidades, estabelecendo a sinergia necessária para alcançar maior grau de competência dos recursos que estão em uso.

Portanto, a partir dessas novas significações, Barney e Hesterly (2007), atualizaram a ferramenta utilizada para a avaliação das dinâmicas de vantagem competitiva no seio das organizações, com o escopo de melhorar a performance dentro de um ambiente competitivo através da análise individual do potencial de cada recurso, seguindo o padrão de quatro conceitos: Valor, Raridade, Imitabilidade e Organização. Assim sendo, insere-se a substituibilidade dentro do âmbito da imitabilidade e modificando o modelo VRIS para o modelo Valor, Raridade, Imitabilidade e Organização (VRIO).

Considerando os supracitados elementos de análise, é possível levantar e verificar hipóteses quanto à eficiência e competitividade das mais diversas estruturas organizacionais existentes em um sistema de produção, tais como: a integração vertical, terceirização de serviços, fusões, aquisições e parcerias.

Para a variável Valor levantem-se as seguintes questões: o recurso é adaptável, para explorar oportunidades e neutralizar ameaças? Contribui de maneira satisfatória para a sobrevivência da firma? É capaz de modificar os padrões do mercado? Pode ser retirado do sistema de produção?

Para mensurar a raridade, analisa-se a quantidade de firmas que possuem o recurso ou que têm potencial para explorá-lo. Não obstante, para a imitabilidade, faz-se o questionamento sobre se o recurso pode ser substituído por outro que desempenha mesma função no sistema; se seu nível de especificidade (seja ela locacional, física, de capital humano, ou de outra ordem) é alto, se há algum tipo proteção (obstáculo) para o desenvolvimento do recurso, e se a questão da imobilidade é muito evidente.

Com um maior nível de complexidade o último parâmetro a ser analisado é a organização. Baseando-se em uma visão holística, verifica-se a necessidade da resposta positiva em relação às últimas três qualidades, para então estudar-se a estrutura formal e informal no seio da organização, e a consequente implicação dessas dinâmicas no âmbito da geração de vantagem competitiva.

Em síntese, o quadro abaixo relaciona as questões fundamentais de cada variável do modelo VRIO, e suas consequentes implicações competitivas no seio da atuação e estruturação das organizações ou sistemas de produção: 


\begin{tabular}{|c|c|c|c|c|}
\hline Valioso? & Raro? & Custoso de Imitar? & Explorado pela organização? & Implicações Competitivas \\
\hline Não & - & - & Não & Desvantagem competitiva \\
\hline Sim & Não & - & Pouco explorado & Paridade Competitiva \\
\hline Sim & Sim & Não & Consideravelmente explorado & $\begin{array}{c}\text { Vantagem Competitiva } \\
\text { Temporária }\end{array}$ \\
\hline Sim & Sim & Sim & Totalmente explorado & $\begin{array}{c}\text { Vantagem Competitiva } \\
\text { Sustentável }\end{array}$ \\
\hline
\end{tabular}

Quadro 1 - Relações fundamentais do modelo VRIO - Valor, Raridade, Imitabilidade e Organização

Fonte: Adaptado de Barney e Hesterly (2011).

A obtenção de vantagem competitiva em e entre sistemas de produção é, portanto, o resultado entre as políticas públicas e privadas e, nesse sentido, dependente dos recursos (valiosos, raros, custosos de imitar) e da maneira como as firmas se organizam para explorá-los.

Quando se avalia os sistemas de produção no escopo de territórios, pondera-se que a obtenção de vantagens competitivas das organizações pertencentes ao território, como um todo, pode relegar maiores níveis de desenvolvimento e performance (seja econômica, ou até mesmo social) ao próprio território.

Coriolano (2003); além de Mariani, Sorio e Arruda (2011) ressaltam que o território é o ponto basilar no qual são empreendidas as estratégias de desenvolvimento local. Portanto pode-se denotar que a garantia de vantagens competitivas aos sistemas de produção de caráter territorial podem perfazer estratégias de obtenção e difusão do desenvolvimento de base local e territorial.

\section{$2 \mathrm{O}$ sistema turístico de Bonito, MS: características estruturais}

Os agentes econômicos que compõem o sistema turístico de Bonito lograram um nível de organização de tamanha complexidade que, para o consumo dos principais produtos turísticos locais, os turistas obrigatoriamente devem sujeitar-se à intermediação de uma agência de viagens sediada no município de Bonito. Isso significa, em termos práticos, que o turista que deseja visitar um dos 50 atrativos turísticos formatados no âmbito de Bonito e adjacências, deve negociar as condições de visitação em uma das 47 agências de turismo cadastradas e localizadas no município; agências estas que estabelecem estreitas relações de coordenação com os atrativos turísticos locais, num caráter verdadeiramente sistêmico (SEPROTUR, 2011).

O florescimento da atividade turística no município de Bonito foi um processo gradativo, que se iniciou em princípios da década de 1970, notadamente por conta dos recursos naturais, paisagísticos e cênicos existentes na região. Somado a esse fato, a recorrência de crises no segmento agropecuário local (que constituía o principal e único motor econômico do sul do até então Estado de Mato Grosso) induziram os proprietários rurais a traçarem estratégias de diversificação e incremento das atividades agrárias, incluindo as modalidades de turismo no espaço rural (BARBOSA; ZAMBONI, 2000).

No correr da década de 1980, a atividade turística no município de Bonito sofre profundas alterações, principalmente por conta: a) do aumento do fluxo de turistas para o município; b) da ampliação do número de atrativos aptos a receber turistas; c) do início de um processo de preocupação com questões ambientais, desencadeando os primeiros trabalhos e pesquisas de manejo e capacidade de carga dos atrativos e; d) da emergência de um crescente cuidado quanto à profissionalização do setor turístico local, o que induziu investimentos nas primeiras agências de turismo e nos pioneiros cursos de formação de guias e técnicos especializados (MARIANI; ARRUDA, 2013).

No ano de 1995, é instituído, para fins consultivos, o Conselho Municipal de Turismo (COMTUR) de Bonito, congregando representantes dos principais segmentos direta ou indiretamente inseridos no escopo do turismo (agências de viagens, hotéis, guias turísticos, atrativos turísticos, produtores rurais, além de membros do poder público local). 
Ainda no mesmo ano, através da instrução normativa n. 009/95, o próprio COMTUR estabelece a obrigatoriedade de utilização do chamado Voucher Único no âmbito da prática do turismo municipal - estabelecendo assim um dos mais exitosos mecanismos de controle e ordenamento de um sistema turístico (VIEIRA, 2003).

O Voucher Único, originalmente, representava um formulário que garantia ao turista a prestação dos serviços por ele contratados - e que, indiretamente, perfazia um subsídio para a produção de informações primárias sobre a situação da atividade turística local, já que no Voucher eram inseridas informações básicas acerca do perfil do turista que visitava Bonito. Contudo, a partir de 2003, a utilização do Voucher Único ganha um nova roupagem, passou a ser impresso (com o respectivo número de controle) pela Prefeitura, sendo entregue sistematicamente às agências de viagem do município, em cinco vias distintas: uma a ser entregue no atrativo visitado; uma destinada ao guia responsável pela condução do passeio; uma oferecida ao turista (ou grupo de turistas), como garantia pela contratação do passeio; uma para a agência que comercializou o passeio/pacote; e uma última que deveria ser entregue periodicamente ao órgão de arrecadação de tributos municipal, com o devido recolhimento do Imposto Sobre Serviços de Qualquer Natureza (ISSQN).

As agências de viagem, atrativos e guias de turismo, para que fossem inseridos na sistemática de funcionamento do Voucher Único, deveriam ser devidamente cadastrados pela Secretaria Municipal de Turismo de Bonito (com a anuência do COMTUR). Assim, nota-se a emergência e paulatina consolidação de um sistema de gestão do turismo que propiciou praticamente a eliminação da sonegação de impostos pelos prestadores de serviços turísticos locais, além do controle da capacidade de carga e utilização dos atrativos turísticos e do estabelecimento de garantias de prestação de serviços e recebimento de remunerações por parte dos agentes atuantes no turismo bonitense.

\section{Procedimentos metodológicos}

O presente estudo guiou-se por uma investigação de abordagem essencialmente qualitativa ao problema de pesquisa a que se pretende responder. Ademais, pode-se classificar o tipo da pesquisa como sendo exploratório, visto que praticamente não há estudos, em literatura brasileira, acerca das dinâmicas de avaliação da vantagem competitiva em sistemas turísticos.

Como estratégia de investigação, lançou-se mão do estudo de caso, que busca analisar profundamente uma determinada unidade, objetivando desvendar características extrapoláveis, de forma dedutiva, para outros casos de caráter mais geral (YIN, 2010).

Os dados primários que embasaram as reflexões em tela foram decorrentes do projeto de dissertação de Arruda (2013), intitulado 'Coordenação e Estruturas de Governança entre agências de turismo e atrativos turísticos em Bonito/MS', desenvolvida junto ao Programa de Pós-Graduação em Administração da Universidade Federal de Mato Grosso do Sul (PPGAd/UFMS). Não obstante, foram feitas coletas de dados secundários e bibliográficos, que também subsidiaram as reflexões fundamentais do artigo em questão.

Foram aplicados sete questionários e cinco entrevistas nos meses de setembro e outubro de 2012. Os agentes efetivamente investigados no escopo do presente trabalho foram os seguintes:

- Quatro agências de turismo que atuam no turismo receptivo em Bonito, MS;

- Três representantes do ambiente institucional local/regional (dois deles atuantes na Fundação de Turismo do Estado de Mato Grosso do Sul - FUNDTUR/MS e um representante da Secretaria de Turismo, Indústria e Comércio de Bonito, MS);

- Dois agentes participantes do ambiente organizacional local (representante da Associação Bonitense de Agências de Turismo - ABAETUR; e da Associação de Atrativos Turísticos de Bonito e Região - ATRATUR); - Três atrativos turísticos na região de Bonito, MS.

Os agentes em tela - diante do caráter qualitativo do trabalho - foram selecionados a partir de critérios de conveniência à elucidação do problema de pesquisa proposto no estudo.

Os recursos intrínsecos ao sistema turístico de Bonito que foram efetivamente analisados a partir do modelo VRIO são os seguintes: 
Atrativos Turísticos Locais; Turistas; Guias Locais; Agências Locais de Turismo; Sistema de Voucher; além das dinâmicas do Conselho Municipal de Turismo. Tais recursos foram selecionados por conta da importância central que apresentam no âmbito da estruturação, coordenação e governança do sistema turístico de Bonito. Ademais, tais recursos foram comparados - a partir de extenso levantamento documental e bibliográfico - às dinâmicas de outros sistemas turísticos, a fim de permitir ao menos um mínimo de comparabilidade das informações levantadas.

\section{Competitividade do sistema turístico de Bonito, MS}

Seguindo as ideias de Barney e Hesterly (2007), os Guias Turísticos e os Turistas podem ser classificados como Recursos Individuais, também conhecidos como recursos humanos, que incluem conhecimento do quadro de colaboradores, habilidade de aprendizagem, facilidade em resolução de conflitos, competência de relacionamento. Dentro do modelo VRIO, pode-se classificar os dois recursos supracitados como valiosos, por serem recursos que contribuem para a sobrevivência do sistema, e também são capazes de modificar os padrões do mercado turístico. Muitos - se não todos - dos outros sistemas turísticos possuem acesso a esses recursos, logo, não são raros ou difíceis de imitar. Portanto esses recursos geram uma paridade competitiva entre o sistema turístico de Bonito, MS em relação a outros sistemas turísticos.

As Agências Locais de Turismo surgem como Recursos Físicos, por constituírem parte da infraestrutura dos diversos agentes do sistema, de maneira comercial, gerando paridade competitiva, por ser um recurso valioso e necessário no sistema produtivo da atividade turística da região, mas sem raridade e com facilidade de imitação.

O COMTUR fica exposto como Recurso Organizacional, que enfatiza a sinergia entre as ações formais e informais dos diversos agentes, dando suporte às ações de planejar, coordenar e controlar. Esse recurso desenvolve uma vantagem competitiva temporária, por ser valioso (explora as oportunidades e neutraliza ameaças) e raro (são poucos os sistemas turísticos que possuem legislação local tão direcionada), mas não é custoso de imitar, pois para o desenvolvimento da atividade turística sustentável é dito como necessidade básica uma legislação local própria.

Os Atrativos Turísticos Locais e o Território são classificados como Recursos Físicos, por serem um dos principais fatores formadores da atividade turística, a paisagem, o ambiente, a fauna, a flora local e a hospitalidade. Fora isso, produzem uma vantagem competitiva sustentada por serem valiosos (contribuem de maneira satisfatória para a sobrevivência do sistema), raros (possuem conjunto de peculiaridades naturais daquele meio ambiente), custosos de imitar (possuem alto nível de especificidade e não podem ser substituídos por outros recursos do sistema turístico de Bonito, MS) e todo o sistema é organizado para explorá-lo (legislação, venda de passeios feita somente por agências locais, guias específicos de acordo com o atrativo e os passeios realizados, conscientização da população sobre o benefício do turismo para o desenvolvimento local, entre outras características).

Por último, e o mais intrigante recurso, o Sistema de Voucher - enfatizado como Recurso Organizacional, dando suporte às ações de planejar, coordenar e controlar as transações do sistema turístico de Bonito, MS, peculiaridade essa que origina uma vantagem competitiva sustentada, por ser um recurso exclusivo do Sistema Turístico em questão. É necessária uma imensa complexidade de organização sistêmica para adotar tal mecanismo. Como consequência disso, percebe-se a dependência de todos os outros recursos em relação ao Sistema de Voucher na realização da atividade turística local. Portanto é um recurso valioso, raro, custoso de imitar, e o sistema é totalmente organizado para sua exploração.

O quadro 02 abaixo sumariza os elementos avaliados e sua consequente implicação no âmbito da geração de vantagem competitiva ao sistema turístico de Bonito: 


\begin{tabular}{|c|c|c|}
\hline $\begin{array}{c}\text { Recursos do Sistema Turístico } \\
\text { de Bonito }\end{array}$ & Classificação & $\begin{array}{c}\text { Nível de Vantagem Competitiva } \\
\text { Gerado }\end{array}$ \\
\hline Guias Turísticos & Recursos Individuais & Paridade Competitiva \\
\hline Turistas & Recursos Individuais & Paridade Competitiva \\
\hline Agências Locais de Turismo & Recurso Físico & Paridade Competitiva \\
\hline Conselho Municipal de Turismo & Recurso Organizacional & Vantagem Competitiva Temporária \\
\hline Atrativos Turísticos Locais & Recurso Físico & Vantagem Competitiva Sustentada \\
\hline Território & Recurso Físico & Vantagem Competitiva Sustentada \\
\hline Sistema de Voucher & Recurso Organizacional & Vantagem Competitiva Sustentada \\
\hline
\end{tabular}

Quadro 02 - Avaliação dos recursos intrínsecos ao sistema turístico de Bonito.

Fonte: Elaborado pelos autores, a partir de Barney e Hesterly (2011).

Portanto notam-se importantes elementos que, do ponto de vista estratégico, podem ser geridos, a fim de que o sistema turístico de Bonito tenha condições para a manutenção e fortalecimento de sua posição como importante destino de ecoturismo regional e nacional, consolidando - por conseguinte - a prerrogativa da atividade do turismo como uma importante fonte de renda e desenvolvimento para os territórios.

\section{Considerações Finais}

A partir da análise do sistema turístico de Bonito, MS por meio do arcabouço teórico adotado neste trabalho, a VBR, verificou-se que os guias turísticos, os turistas, as agências locais de turismo, COMTUR, os atrativos turísticos locais, o território e o sistema de Voucher são - de forma conjunta - recursos indispensáveis e que relegam competitividade em diferentes níveis a esse sistema produtivo.

Verificou-se que o próprio consumidor final (turista) é um importante recurso que, na forma genérica, consegue causar uma paridade competitiva, entretanto, se bem alocado e 'atendido' - conforme a configuração territorial e os preceitos da hospitalidade -, consegue transmitir mais valor e dar maior competitividade ao sistema turístico por meio do marketing 'boca-a-boca' favorável, sugerindo visitas, propalando a temática da preservação ambiental e também outros aspectos.

De acordo com a administração dos recursos naturais formadores dos atrativos, é possível conciliar a sustentabilidade econômica, ambiental e social do sistema turístico de Bonito, MS. Primeiramente pela utilização dos recursos conscientes que poderão ser explorados a longo prazo, gerando benefício econômico pela heterogeneidade dos produtos turísticos ofertados e, ao mesmo tempo, desenvolvimento social à região pela criação de postos de trabalho e desenvolvimento intelectual dos cidadãos.

Mais voltado ao ambiente institucional é inerente o importante papel do COMTUR, tanto pela gestão atual quanto para seus feitos já realizados. Nota-se tal fato na criação e a utilização do Sistema de Voucher, que é considerado um grande diferencial do sistema estudado, objeto esse que causou grande organização entre os agentes e suas transações que junto das atuações rotineiras do Conselho Municipal (leia-se reuniões com participação de representantes de cada agente por meio de suas associações) fez com que Bonito se tornasse um destino turístico cada vez mais procurado.

Vale ressaltar que o estudo realizado não possui caráter conclusivo, por conta da necessidade de maior incorporação da análise das transações e a caracterização destas na relação de cada agente. Lembrando também da inserção de um diagnóstico perante a adoção das estratégias de governança dos agentes aqui não abordados, hotéis, empresas de transporte, e outros.

Ademais, os pressupostos comportamentais e as unidades de análise classificadas pela Nova Economia Institucional formam interessantes temáticas de pesquisa, a fim de verificar o grau de oportunismo e o padrão da transação entre cada agente, ou até mesmo de voltar-se mais firmemente ao ambiente organizacional constituído pelas associações do Sistema Turístico de Bonito, MS. 


\section{Referências}

ARRUDA, D. O. Coordenação e Estruturas de governança entre agências de turismo e atrativos turísticos em Bonito/MS. 2013. 125f. Dissertação (Mestrado em Agronegócios) Universidade Federal de Mato Grosso do Sul (UFMS), Campo Grande, MS, 2013.

BARBOSA, M. A. C.; ZAMBONI, R. A. Formação de um cluster em torno do turismo de natureza sustentável em Bonito-MS. Brasília, DF: IPEA/CEPAL, 2000. 47p.

BARNEY, J. B. Firm Resources and Sustained Competitive Advantage. Journal of Management, v. 17, n. 01, p. 99-120, mar. 1991.

. Strategic factor markets: expectations, luck, and business strategy. Management Science, Hanover, EUA, v. 32, n. 10, p. 1231-1241, out. 1986.

BARNEY, J. B.; HESTERLY, W.S. Administração estratégica e vantagem competitiva: conceitos e casos. 3. ed. São Paulo: Pearson Prentice Hall, 2011. 432 p.

. Administração estratégica e vantagem competitiva. São Paulo: Pearson Prentice Hall, 2007. 352 p.

BARNEY, J. B.; KETCHEN JR, D.; WRIGHT, M. The future of resource-based theory: revitalization or decline? Journal of Management, v. 37, n. 05, p. 1299-1315, set. 2011.

BARZEL, Y. Measurement cost and the organization of markets. The Journal of Law and Economics, Chicago, v. 25, p. 27-48, abr. 1982.

BENI, M. C. Análise estrutural do turismo. 10. ed. São Paulo: Ed. SENAC, 2003.

COASE, R. H. The nature of the firm. Economica, London, v. 04, n. 16, p. 386-405, nov. 1937.

CORIOLANO, L. N. M. T. O turismo de inclusão e o desenvolvimento local. Fortaleza: FUNECE, 2003.

FARINA, E. M. M. Q. Competitividade e coordenação de sistemas agroindustriais: um ensaio conceitual. Gestão \& Produção, São Carlos, SP, v. 06, n. 03, p. 147-161, dez. 1999.

FOSS, K.; FOSS N. J. Resources and transaction costs: how property rights economics furthers the resourcebased view. Strategic Management Journal, v. 26, n. 06, p. 541-553, jun. 2005.

MARIANI, M. A. P.; SORIO, A.; ARRUDA, D. O. Carne ovina, turismo e desenvolvimento local: potencialidades para o Mato Grosso do Sul. Interações, Campo Grande, MS, v. 12, n. 01, p. 31-39, jan./jun. 2011.
MARIANI, M. A. P.; ARRUDA, D. O. Coordenação e Estruturas de Governança em um Sistema Produtivo do Turismo em Espaço Rural. In: CONGRESSO BRASILEIRO DE ECONOMIA, ADMINISTRAÇÃO E SOCIOLOGIA RURAL - SOBER, 51., 2013, Belém, PA. Anais... Belém, 2013. p. 01-18.

MASSUKADO-NAKATANI, M. S.; TEIXEIRA, R. M. Resource-based view as a perspective for public tourism management research: evidence from two Brazilian tourism destinations. Brazilian Administration Review, Curitiba, v. 06, n. 01, p. 62-77, jan./jun. 2009.

NORTH, D. C. Institutions. Journal of Economic Perspectives, v. 05, n. 01, p. 97-112, jan./mar. 1991.

NORTH, D. Institutions, institutional change and economic performance. New York: Cambridge University Press, 2004.

OLIVER, C. Sustainable competitive advantage: combining institutional and resource-based views. Strategic Management Journal, v. 18, n. 09, p. 697-713, out. 1997.

PENROSE, E. T. The theory of the growth of the firm. New York: Wiley Press, 1959.

SECRETARIA DE ESTADO DE DESENVOLVIMENTO AGRÁRIO, DA PRODUÇÃO, DA INDÚSTRIA, DO COMÉRCIO E DO TURISMO - SEPROTUR/MS. Plano de Desenvolvimento Integrado do Turismo Sustentável (PDITS) - Serra da Bodoquena. Campo Grande: SEPROTUR - MS/MTUR, 2011. 497p.

VIEIRA, J. F. L. Voucher único um modelo de gestão da atividade turística em Bonito, MS. Dissertação (Mestrado em Desenvolvimento Local) - Universidade Católica Dom Bosco, Campo Grande, MS, mar. 2003.

WERNERFELT, B. A resource-based view of the firm. Strategic Management Journal, v. 5, n. 2, p. 171-180, abr./ jun. 1984.

WILLIAMSON, O. The new institutional economics: taking stock, looking ahead. Journal of Economic Literature, v. 38, p. 595-613, set. 2000.

WILLIAMSON, O. The Mechanisms of Governance. Oxford, UK: Oxford University Press, 1996. 429p.

WILLIAMSON, O. The economic institutions of capitalism: firms, markets, relational contracting. New York: The Free Press, 1985. 450p.

WILLIAMSON, O. Transaction-Cost Economics: the governance of contractual relations. Journal of Law and Economics, Chicago, v. 22, n. 02, p. 233-261, out. 1979.

YIN, R. K. Estudo de caso: planejamento e métodos. 4. ed. Porto Alegre: Ed. Bookman, 2010. 